\title{
Protect, manage and then restore lands for climate mitigation
}

\author{
Susan C. Cook-Patton ${ }^{1 凶}$, C. Ronnie Drever ${ }^{2}$, Bronson W. Griscom ${ }^{\circledR}{ }^{3}$, Kelley Hamrick ${ }^{1}$,

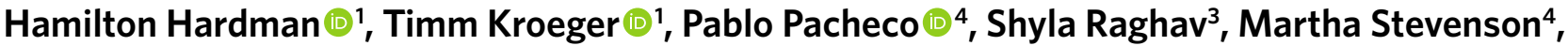 \\ Chris Webb ${ }^{5}$, Samantha Yeo ${ }^{1}{ }^{1}$ and Peter W. Ellis ${ }^{6}$
}

\begin{abstract}
Limited time and resources remain to constrain the climate crisis. Natural climate solutions represent promising options to protect, manage and restore natural lands for additional climate mitigation, but they differ in (1) the magnitude and (2) immediacy of mitigation potential, as well as (3) cost-effectiveness and (4) the co-benefits they offer. Counter to an emerging preference for restoration, we use these four criteria to propose a general rule of thumb to protect, manage and then restore lands, but also show how these criteria explain alternative prioritization and portfolio schemes. This hierarchy offers a decision-making framework for public and private sector actors to optimize the effectiveness of natural climate solutions in an environment in which resources are constrained, and time is short.
\end{abstract}

W e need drastic reductions in emissions to-and increased removals from-the atmosphere to avoid the worst effects of climate change ${ }^{1}$. Reducing fossil fuel emissions is the most critical action ${ }^{1-4}$, but natural climate solutions (NCS) are also required to meet this goal ${ }^{5}$. The latter are 'additional' land-stewardship actions that capture or reduce greenhouse gas (GHG) emissions by protecting existing ecosystems, improving the management of working lands or restoring natural ecosystems ${ }^{6-8}$. Unlike emergent technologies, such as the direct air capture of carbon dioxide $\left(\mathrm{CO}_{2}\right)$, NCS are often lower cost, more readily available and can improve air, soil and water quality?

Here we propose the 'NCS hierarchy' as a framework for public and private sector decision-makers that suggests considering NCS related to protection, improved management and then restoration when prioritizing among different NCS (Fig. 1). Despite the need for-and recent indications of-an increased investment in NCS to respond to the urgency of climate change, resource constraints remain and decision-makers need to select among options. We describe a general hierarchy based on four principal criteria: (1) the magnitude and (2) immediacy of mitigation potential, (3) cost-effectiveness and (4) co-benefits. However, we note that protection, improved management and restoration NCS are not mutually exclusive; in planning and practice, these actions can be highly complementary ${ }^{10}$. As the priorities at the national and local scales depend on context (for example, biophysical, political, institutional, economic and socio-cultural factors), we also show how this framework provides a process to improve the overall impact of climate mitigation efforts, rather than a rigid set of prescriptions.

\section{NCS hierarchy}

Natural resource management has utilized mitigation hierarchies for over a century, stretching back to the conservation and preservation theories of Pinchot and Muir, respectively ${ }^{11}$. In 2012, a mitigation hierarchy (hereafter 'biodiversity hierarchy') was formalized to mitigate the negative effects of economic development projects on biodiversity and ecosystem services ${ }^{12,13}$ and to support global biodiversity conservation ${ }^{14}$. The first three steps of the biodiversity hierarchy are (1) avoid negative impacts to biodiversity, (2) minimize unavoidable impacts and (3) remediate negative impacts by restoring the affected sites or species. Recently, the Science Based Targets Network, a collaboration of non-governmental organizations, business associations and consultancies, developed a hierarchy to help private and public sector entities advance general sustainability goals ${ }^{15}$. Their version, the $\mathrm{AR}^{3} \mathrm{~T}$ framework (avoid, reduce, regenerate, restore and transform), effectively shares the first two steps of the biodiversity hierarchy but differentiates actions that 'remediate' (in the case of the biodiversity hierarchy) into those that improve the ecosystem functions within the existing land uses ('regenerate') from actions that fully re-establish natural cover in places previously converted ('restore'). The Science Based Targets Network also included a transform category, which we acknowledge is essential but do not further expand on here. Transform actions include system- and jurisdictional-wide changes needed to tackle large-scale environmental problems (for example, granting and enforcing tenure rights) that are additive rather than sequential to the $\mathrm{AR}^{3}$ steps ${ }^{15}$.

Our NCS hierarchy focuses specifically on reducing GHG emissions or increasing carbon sequestration with constraints to ensure no negative impacts on biodiversity or human well-being ${ }^{8,16}$. NCS readily align with the biodiversity hierarchy and the $\mathrm{AR}^{3} \mathrm{~T}$ framework (Supplementary Fig. 1). Protection NCS avoid emissions from the conversion of forests, grasslands or wetlands, or from changing wetland hydrology (for example, when salt marshes are diked) ${ }^{8}$. Improved management NCS minimize and/or reduce emissions in working agricultural and forest lands. Improved manure management reduces methane emissions ${ }^{6}$ and improved timber felling techniques reduce damage to the residual forest stand ${ }^{17}$. Improved management NCS can also regenerate carbon pools when, for example, cover crops increase soil carbon sequestration ${ }^{7}$. Finally, restoration NCS remediate and/or restore forest, wetland and grassland cover where those ecosystems historically occurred. We note that 'restoration' can also describe a diverse suite of actions to recover

The Nature Conservancy, Arlington, VA, USA. ${ }^{2}$ Nature United, Ottawa, Ontario, Canada. ${ }^{3}$ Conservation International, Arlington, VA, USA. ${ }^{4}$ World Wildlife

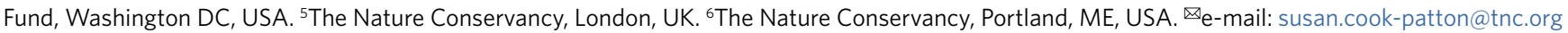



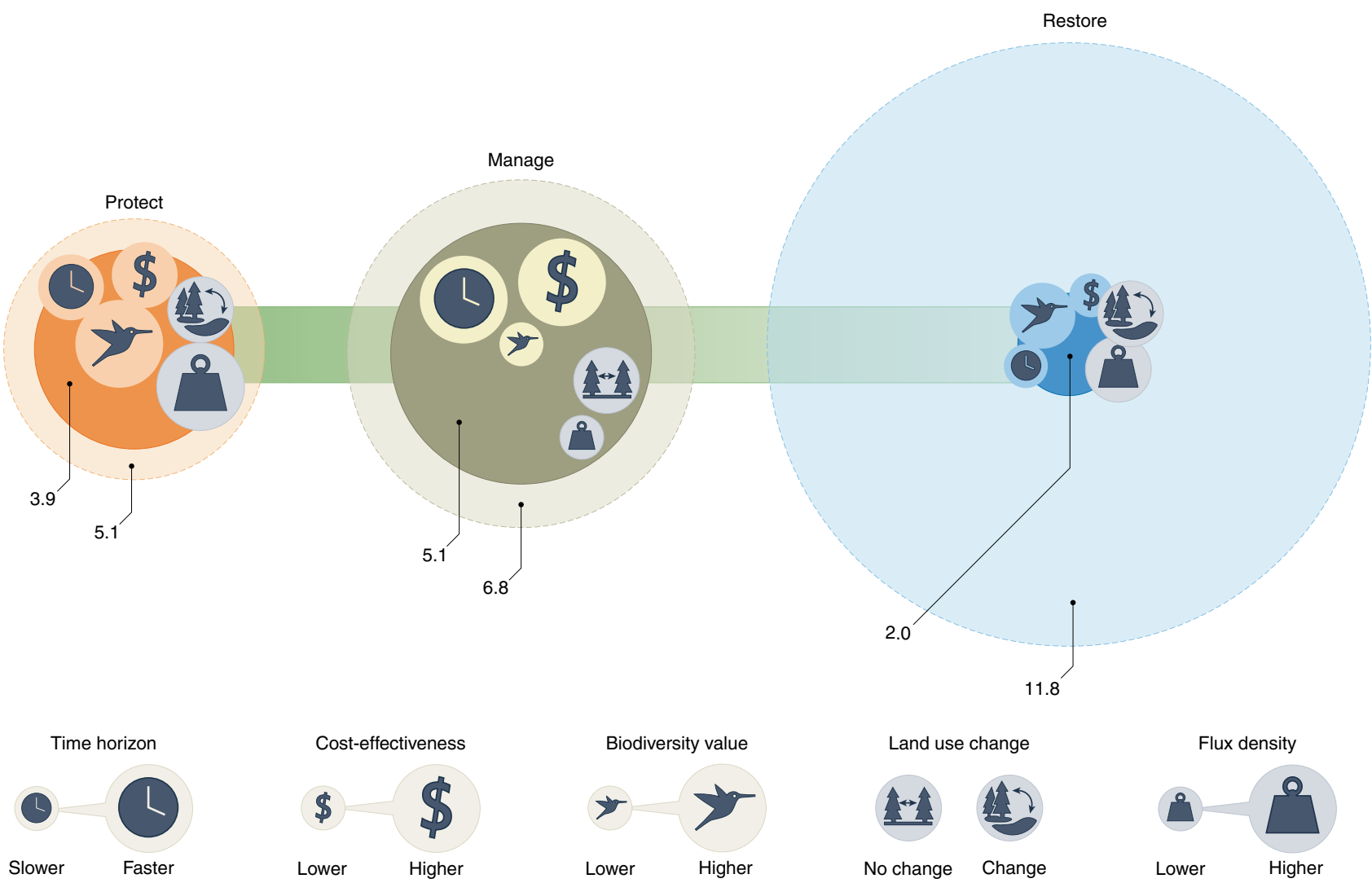

Fig. 1 | The NCS hierarchy starts with the protection of ecosystems and flows to improved management and restoration. Although the NCS hierarchy describes an order, in practice, protection (orange), improved management (green) and restoration (blue) can be complementary and part of a portfolio of NCS to optimize climate mitigation outcomes. The dashed circles indicate the global maximum mitigation potential and the solid circles indicate the mitigation potential at $\leq \mathrm{US} \$ 100 \mathrm{tCO}_{2} \mathrm{e}^{-1}$ with numbers to indicate estimated $\mathrm{GtCO}_{2} \mathrm{e} \mathrm{yr} \mathrm{r}^{-1}$ in 2030 . Icons are described in the legend at the bottom and a larger size indicates more positive outcomes (for example, faster time horizon or higher cost-effectiveness). Note that the biodiversity benefits reflect on-site per hectare benefits and are somewhat hypothetical in the absence of a systematic review of biodiversity outcomes across NCS. We include icons to show whether land use change is required and relative flux density per hectare, which are additional to the four criteria we describe but influence the order of the NCS hierarchy. Credit: Vin Reed.

degraded, damaged or destroyed ecosystems ${ }^{18}$. This broader definition could encompass some improved management NCS, so here we use 'restoration' narrowly to describe recovering an ecosystem that has been lost. Restoration NCS do not include replacing native with non-native ecosystems (for example, the afforestation of natural grasslands), which have negative biodiversity consequences and ultimately limited mitigation potential ${ }^{19}$.

\section{The need for a NCS hierarchy}

As conservation practitioners and scientists at three international non-governmental organizations, we often observe land-based climate mitigation strategies that prioritize restoration over improved management or protection. In the public sector, for example, the Canadian government announced a notable Can $\$ 3.8$ billion investment in NCS over the next 10 years, allocating $81 \%$ to restoration (that is, planting 2 billion trees), but only $3 \%$ to improved land management and $16 \%$ to protection ${ }^{20}$. This relative allocation contrasts with recent research, which suggests that protection and improved management NCS offer the most cost-effective options for nature-based climate mitigation in Canada. More broadly, countries that include the land sector in their nationally determined contributions to the Paris Agreement tend to include protection, afforestation and forest restoration, rather than the improved management of ecosystems ${ }^{21}$. This restoration tilt is also evident in forest sector commitments, as $42 \%$ of countries include afforestation and reforestation, 38\% include forest management and 32\% focus on avoided deforestation ${ }^{22}$.

The private sector shows similar patterns. The Carbon Removal Corporate Action Tracker includes 93 corporate pledges and shows that-among those that provide detail on the NCS actions-78\% mention restoration, $41 \%$ mention protection and $43 \%$ mention improved land management ${ }^{23}$, although this tool is biased towards corporations that pledge removals. In contrast, land sector emissions from corporate supply chains stem principally from land conversion and management, and thus reducing these activities is critical to decrease supply-chain climate impacts ${ }^{21,24}$. Over 400 companies have pledged to remove deforestation from their supply chains, but with little progress to date ${ }^{25}$, and in the meantime there has been a surge of corporate tree-planting commitments ${ }^{4}$. Further, notable corporate commitments have prioritized removals rather than reduced emissions (for example, ref. ${ }^{26}$ ). However, as we describe below, failure to consider the full range of NCS systematically and comprehensively will unnecessarily constrain efforts to address global warming.

\section{Four criteria of the NCS hierarchy}

Four interrelated criteria influence the general order of the NCS hierarchy and can explain variations to the hierarchy in practice and by location (Fig. 1). These criteria are (1) the size of mitigation potential, (2) cost-effectiveness, (3) time horizon and (4) 
co-benefits. Additional factors may drive NCS feasibility in a given geography, such as technical constraints, availability of ecosystems to conserve or manage and/or policies or regulations that incentivize or disincentivize NCS adoption ${ }^{3,27}$. Further, the preferences and development needs of local communities are critical and will influence the durability of a NCS intervention ${ }^{4,28}$. However, here we focus on criteria that are quantifiable at the global level, recognizing that other factors are best assessed at local levels with impacted communities ultimately determining priorities for climate action.

The size of the mitigation potential (typically estimated in million metric tons of $\mathrm{CO}_{2}$-equivalents per year $\left(\mathrm{MtCO}_{2} \mathrm{e} \mathrm{yr}^{-1}\right)$ ) refers to removed carbon or reduced GHG emissions that, importantly, are additional to a business-as-usual baseline. Additionality means, for example, that protection NCS should focus on ecosystems at a high risk of losing carbon stores ${ }^{29}$. Mitigation potential is a product of the extent of opportunity (for example, number of hectares restored or heads of cattle affected) and the change in $\mathrm{GHGs}\left(\mathrm{CO}_{2} \mathrm{e}\right)$ per unit extent ${ }^{8}$. The latter we term 'flux density', in which a positive flux density is a reduction in emissions or an increase in removals relative to business as usual. Thus, a high potential can be a function of a large extent, a high positive flux density or both. We note that mitigation potential is most useful for selecting NCS or geographies with a high opportunity to achieve scale. For example, reforestation offers more than six times the mitigation potential of avoided forest conversion in the United States ${ }^{6}$, which suggests that the former may be better suited for initiatives with large-scale ambitions. In contrast, flux density is better suited for project-level decisions to identify the NCS or geographies with the greatest mitigation returns per unit extent.

An additional criterion is cost-effectiveness, which measures the resource investment required per $\mathrm{tCO}_{2} \mathrm{e}$ reduced. Relevant costs include the sum of (1) net cost to land managers (the sum of the initial NCS implementation costs, opportunity costs-foregone profits associated with switching land uses-and transaction costs) and (2) implementation and transaction costs to others whose actions are also required (for example, government programmes to conduct outreach or enrol land managers). Here we estimated cost-effectiveness as the mean marginal abatement cost (MAC) per NCS by reanalysing data from prior publications ${ }^{6-8}$ (see Supplementary Methods). NCS can range from highly cost-effective (low, zero or even negative net cost per $\mathrm{tCO}_{2} \mathrm{e}$, for example, when changes in agricultural practices increase farm profitability) to marginally cost-effective (high net cost per unit GHG mitigation, for example, urban tree planting) $)^{6,8,30}$ (Fig. 2 and Supplementary Figs. 2 and 3). With limited resources, it makes sense to target the most cost-effective NCS first. However, the pool of NCS with a low cost per unit mitigation can be limited, which requires consideration of options with higher unit costs. In Canada, for example, only one-third of the total mitigation potential is estimated to be available at $\leq \mathrm{Can} \$ 50 \mathrm{tCO}_{2}^{-1}$ (ref. ${ }^{7}$ ). High costs may also be due to labour-intensive NCS projects, which represent opportunities to create jobs as part of green recovery plans after the COVID-19 pandemic, and governments may prioritize NCS that can stimulate green economic activity. Further, the above costs do not capture non-monetizable values, such as urban shade and mental health benefits.

The time horizon needed to realize a positive change in flux after implementation is another important criterion ${ }^{3}$. For some NCS, changes in flux occur upon implementation or shortly thereafter. For example, manure acidification can rapidly reduce methane emissions $^{31}$. Other NCS take longer to achieve a net positive flux. For example, peatland rewetting releases methane and increases emissions in the short term, but eventually reduces emissions by halting soil carbon loss ${ }^{32}$. Thus, both mitigation and cost-effectiveness depend on the accounting horizon. For example, restoration of forest cover in Canada provides limited mitigation potential within the first decade of planting, but offers the highest potential of all the examined NCS 20 years after tree planting ${ }^{7}$. As this example demonstrates, a long time horizon does not mean a NCS should be avoided as most NCS require acting now to yield meaningful GHG reductions in time to constrain the climate crisis $^{33}$.

Here we focus on time horizon, given the need for near-term actions to constrain the climate crisis, but another important temporal component is 'permanence', or the likelihood of reversals due to anthropogenic or natural disturbance ${ }^{34}$. Approaches to deal with project-level permanence risk include buffer pools or discounting to account for the potential project failure. There are also institutional conditions, such as tenure security and benefit-sharing mechanisms that can improve permanence ${ }^{35,36}$. Regardless, mitigation actions with a higher permanence should be prioritized over actions with higher reversal probabilities.

A fourth criterion relates to the ability of each NCS to deliver benefits beyond climate mitigation. NCS can improve human health and livelihoods, support Indigenous cultures, protect biodiversity and increase resilience to future climate impacts ${ }^{37-40}$. Co-benefits can mitigate some feasibility constraints. For example, on-site co-benefits of agroforestry, such as heat mitigation for people and livestock ${ }^{41}$, may help to sway potential adopters towards NCS. The financial value of these on-site co-benefits can be captured in the cost-effectiveness criterion because they reduce the opportunity costs for landowners. For example, reduced heat stress from agroforestry can increase livestock productivity to offset the tree-establishment costs ${ }^{42}$. Landowners may also incorporate non-financial co-benefits (for example, reduced human heat stress from agroforestry) into their cost-effectiveness decisions, although these are highly context-dependent and thus difficult to quantify. Compensating landowners for off-site co-benefits may further improve financial feasibility (for example, through payments for environmental services, such as improved downstream water quality ${ }^{43}$ ). However, trade-offs between climate mitigation and co-benefits are possible. For example, restoring tree cover via plantation forestry may offer a lower-cost climate mitigation than the restoration of native forest, but a lower or negative biodiversity value $^{44}$. Similarly, protecting forests with the highest carbon stores may not protect forests with the highest biodiversity value ${ }^{45}$.

These criteria can also help prioritize actions within a single NCS. For example, there are multiple improved forest-management practices (for example, extended rotations, reduced impact logging and partial set asides in planned harvest blocks ${ }^{8,17}$ ) and multiple ways to restore forest cover (such as timber plantations, agroforestry systems, tree planting to restore native forest and natural forest regrowth ${ }^{46}$ ). Each of these will vary in mitigation potential, cost-effectiveness, time horizon and co-benefits ${ }^{47}$.

\section{Why protection is first}

Protection NCS are first in the hierarchy because they can offer a high per-hectare mitigation that can be realized quickly and at a comparatively low cost per $\mathrm{tCO}_{2} \mathrm{e}$, typically with many co-benefits. Protection NCS also align with global commitments to stop deforestation, limit forest degradation and halt biodiversity loss. We describe each of these in more detail below.

Natural ecosystems can store large amounts of carbon, sequester additional carbon and represent more-stable and long-term carbon stores compared with working and restored land $s^{48,49}$. Avoiding the conversion of mature and young secondary ecosystems prevents carbon from being released into the atmosphere and maintains their ability to keep sequestering carbon $^{50}$. Protection NCS can also offer a higher flux density than improved management or restoration NCS (Supplementary Table 1). For example, avoiding mangrove drainage could prevent $29 \mathrm{tCO}_{2} \mathrm{ha}^{-1} \mathrm{yr}^{-1}$ on average $\mathrm{e}^{51}$, which far outweighs the flux density from improved forest management $\left(0.2 \mathrm{tCO}_{2} \mathrm{ha}^{-1} \mathrm{yr}^{-1}\right.$ on average $\left.{ }^{8}\right)$ or natural forest regrowth $\left(13.1 \mathrm{tCO}_{2} \mathrm{ha}^{-1} \mathrm{yr}^{-1}\right.$ on average $\left.{ }^{46}\right)$. 
a

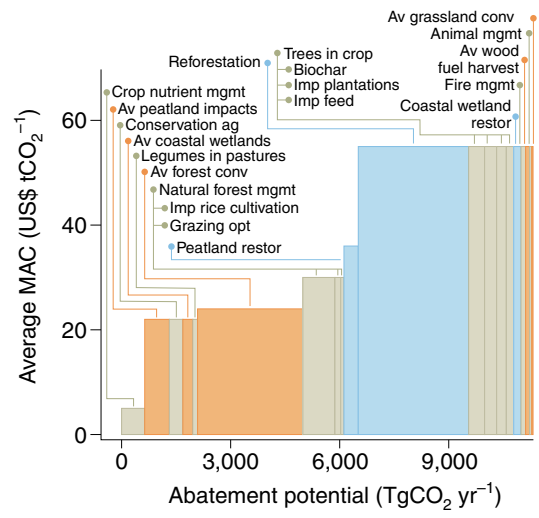

b

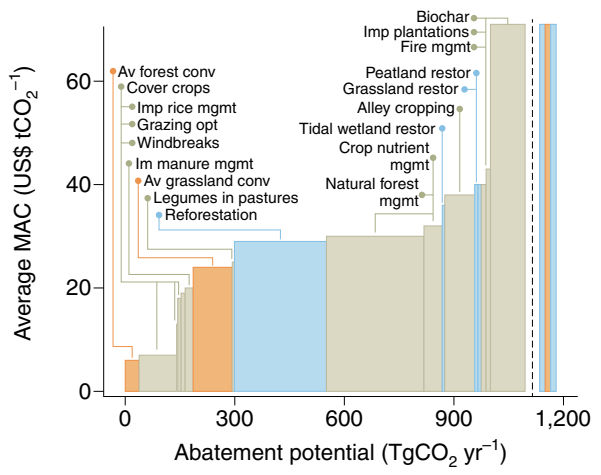

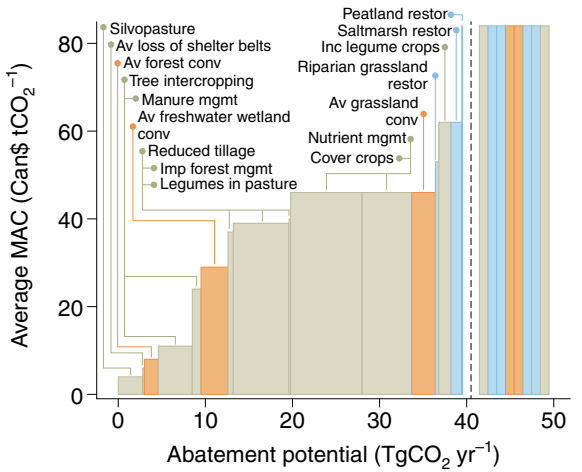

Management $\square$ Protection $\square$ Restoration

Fig. 2 | Average MAC for NCS available for $\leq \$ 100 \mathbf{t C O}_{\mathbf{2}} \mathbf{e}^{-\mathbf{1}}$. a-c, Global ${ }^{8}$ (a) and US $\mathbf{~}^{6} \mathbf{b}$ ) estimates are in US dollars, and Canadian ${ }^{7}$ (c) estimates are in Canadian dollars. Comparisons should not occur across geographies given the differences in the underlying methods (Supplementary Methods). The bar height indicates the average MAC and the width indicates the mitigation potential available for $\leq \$ 100 \mathrm{tCO}_{2} \mathrm{e}^{-1}$ in 2030 (2025 for the United States). The bars are ordered from left to right by lowest to highest unit cost $\left(\$ \mathrm{tCO}_{2} \mathrm{e}^{-1}\right)$ and then largest-to-smallest mitigation potential. We aggregated labels for visual clarity; when labels share a branch, the left-to-right position of the circular node indicates the left-to-right position in the chart. As most NCS have some mitigation potential at low and high costs, we show how these patterns change if there is no cost threshold (Supplementary Fig. 2) or if the cost threshold is $\leq \$ 50 \mathrm{tCO}_{2} \mathrm{e}^{-1}$ (Supplementary Fig. 3). Note that in the United States and Canada, there are NCS with no opportunity at $\leq \$ 100$ tCO $\mathrm{e}^{-1}$, which we indicate with uniformly sized bars to the right of the vertical dashed line, ranked by order when unconstrained by cost (Supplementary Fig. 2). In the United States, these are urban reforestation, avoided seagrass loss and seagrass restoration (left to right). In Canada, these are biochar, urban canopy cover, seagrass restoration, avoided seagrass disturbance, avoided peatland disturbance, freshwater mineral wetland restoration, restoration of forest cover and riparian tree planting (left to right). Ag, agriculture; av, avoided; conv, conversion; crop, cropland; imp, improved; inc, increased; mgmt, management; opt, optimization; restor, restoration.

Protection NCS can also often offer large near-term climate mitigation ${ }^{49}$. Ecosystems can rapidly lose carbon when disturbed, such as when forests are harvested or grasslands are tilled for crops. In many cases, it can take decades to centuries for the carbon to recover. Loss of this 'irrecoverable' carbon is an effectively permanent debit from the remaining global carbon budget for keeping global warming below catastrophic levels ${ }^{52}$. Prioritizing the protection of the irrecoverable carbon stores at risk of disturbance is critical as improved management and restoration NCS will be unable to compensate for this loss on meaningful timescales.

Protection NCS may also offer more cost-effective mitigation than improved management or restoration, although not always (Fig. 2). The latest global estimates, which stem from multiple recent publications $s^{8,46,53,54}$, suggest that at $\leq \mathrm{US} \$ 100 \mathrm{tCO}_{2} \mathrm{e}^{-1}$, protection NCS offer up to $4,245 \mathrm{MtCO}_{2} \mathrm{e} \mathrm{yr}^{-1}$ in 2030, compared with 2,884

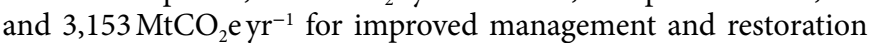
NCS, respectively. This pattern is strongest for the global estimates (Fig. 2), but protection NCS also offer substantial low-cost per $\mathrm{tCO}_{2} \mathrm{e}$ potential in the United States and Canada (Supplementary Figs. 2 and 3 ).

There are many potential co-benefits linked to the protection of ecosystems, such as the protection of Indigenous peoples and local communities' livelihoods and cultures ${ }^{40}$, avoidance of extreme heat conditions ${ }^{55}$ and reduced negative impacts to coastal communities from rising seas and other coastal hazards ${ }^{56}$. Intact forest ecosystems are noted for their exceptional value with respect to habitat for biodiversity, water provisioning and maintaining human health ${ }^{57}$. Additionally, given the many goals to conserve biodiversity and end deforestation, private and public sector actors can address both biodiversity and climate mitigation goals with the single action of ecosystem protection ${ }^{25,58}$. Protection of forests may also be one of the most cost-effective ways to prevent zoonotic virus spillover to humans, as financing efforts to stop deforestation amounts to just
$2 \%$ of the cost of the COVID-19 pandemic ${ }^{59}$. However, although protection NCS support in situ biodiversity, the leakage or the displacement of activities from one area to another must be minimized to reap the biodiversity benefit, as well as the climate mitigation benefit $^{38}$. Solutions to minimize leakage include, for example, improved agricultural practices to reverse land degradation and preventing the clearing of forests for new agricultural lands ${ }^{10}$, or jurisdictional approaches such as REDD $+{ }^{60}$.

Finally, failure to protect native ecosystems can undermine the potential effectiveness of other NCS in the same area. For example, relying on natural forest regrowth to restore forest cover can be cost-effective ${ }^{61}$, but it depends on having nearby seed sources ${ }^{62}$. Failure to protect adjacent forests can thus preclude using natural forest regrowth as a climate solution.

\section{Why improved management is next}

Improved management NCS are second in the hierarchy primarily because they often offer lower-cost mitigation potential than restoration NCS (Fig. 2). They can also deliver mitigation alongside commodity production and are thus less prone to leakage issues than protection or restoration $\mathrm{NCS}^{38}$. However, as noted above, they usually have a lower flux density than protection NCS. Unlike protection NCS, improved management NCS also include carbon removals from the atmosphere-in addition to avoided emissionsand removals may offer lower mitigation when deployed at scale ${ }^{63,64}$.

At the global level, improved management NCS account for two-thirds of the mitigation potential available at low cost in $2030\left(\leq \mathrm{US} \$ 30 \mathrm{tCO}_{2} \mathrm{e}^{-1}\right)$. This pattern is further accentuated in national-level analyses (Supplementary Fig. 3). In Canada, improved management NCS account for $85 \%$ of the mitigation potential in 2030 with mean MAC of $\leq \mathrm{Can} \$ 10 \mathrm{tCO}_{2} \mathrm{e}^{-1}$ and $75 \%$ of the potential with mean MAC of $\leq \mathrm{Can} \$ 50 \mathrm{tCO}_{2} \mathrm{e}^{-1}$. Similarly, in the United States, improved management NCS account for $75 \%$ of the total mitigation 
potential in 2025 with mean MAC of $\leq \mathrm{US} \$ 10 \mathrm{tCO}_{2} \mathrm{e}^{-1}$ and $55 \%$ of the total mitigation potential with mean MAC of $\leq \mathrm{US} \$ 50 \mathrm{tCO}_{2} \mathrm{e}^{-1}$.

Improved management NCS also require little-to-no changes in land use (for example, from cropland to forest). Displacing alternative land uses may result in a higher average MAC than estimated here for protection and restoration NCS (Fig. 2), as land cost data used to estimate opportunity costs may be systematically biased $\operatorname{low}^{65,66}$. This bias would make improved management NCS even more cost-effective relative to other NCS.

The mitigation potential of many improved management NCS can be realized almost immediately, especially those that reduce emissions ('minimize') rather than increase ('regenerate') stocks. For example, on implementation or shortly thereafter, an improved fertilizer application reduces $\mathrm{NO}_{x}$ emissions ${ }^{67}$, and reduced-impact logging techniques can halve logging emissions ${ }^{17}$. However, improved management NCS usually have a lower flux density than either protection or restoration NCS (Supplementary Table 1).

Improved management NCS produce multiple co-benefits. Cover crops can improve soil health and boost yields ${ }^{68}$. Trees along riparian corridors in agricultural lands can help to protect water quality $^{69}$ and provide habitat for biodiversity ${ }^{70}$. We hypothesize that the in situ biodiversity benefits of improved management are smaller than those linked to protection NCS or the restoration of native ecosystems (Fig. 1), given the high biodiversity value of intact landscape ${ }^{57}$ and the common intention to restore native biodiversity via restoration projects ${ }^{71}$. However, improved management NCS may have substantial off-site benefits when, for example, improved forest management practices protect the integrity of downstream freshwater and marine ecosystems ${ }^{72}$.

\section{Why restoration is third}

Restoration NCS have the potential to offer substantial climate mitigation. Indeed, the restoration of forest cover represents the single largest NCS based on the global biophysical potential ${ }^{8}$. However, restoration NCS are third in the hierarchy because failure to protect intact lands where conversion or disturbance pressures are high will release large amounts of carbon that cannot be balanced in a timely manner by the gradual carbon accrual from restoration. Moreover, the mitigation from restoration NCS primarily stems from removals, which may be less effective than avoided emissions at lowering atmospheric GHG concentrations ${ }^{63,64}$. Additionally, restoration NCS can have high costs and feasibility constraints (Fig. 1).

Restoration NCS can be less cost-effective than protection or improved management NCS due to high opportunity and implementation costs. For example, in Canada only three of the eight restoration NCS have any mitigation potential in 2030 at $\leq$ Can $\$ 100 t_{C O} \mathrm{e}^{-1}$ (Fig. 2c) and those three restoration NCS have some of the highest average MACs compared with other NCS with mitigation potentials at $\leq \mathrm{Can} \$ 100 \mathrm{tCO}_{2} \mathrm{e}^{-1}$. Similarly, in the United States, restoration NCS account for about $4 \%$ of the total mitigation potential in 2025 among NCS with mean MAC $\leq \mathrm{US} \$ 10 \mathrm{tCO}_{2} \mathrm{e}^{-1}$. In the tropics, a spatially explicit analysis of the MAC of avoided deforestation versus reforestation found that the former offered seven to nine times more mitigation potential at $\leq \mathrm{US} \$ 20 \mathrm{tCO}_{2} \mathrm{e}^{-1}$ $\left(\right.$ ref. ${ }^{54}$ ). Globally, no restoration NCS has an estimated mean MAC of $\leq \mathrm{US} \$ 30 \mathrm{tCO}_{2} \mathrm{e}^{-1}$ in 2030 (Fig. 2), even though peatland restoration offers some potential at $\leq \mathrm{US} \$ 10 \mathrm{tCO}_{2} \mathrm{e}^{-1}$.

However, net costs depend on location as well as on the approach used to restore native cover. Lower-cost options can be readily available. For example, relying on natural regrowth where possible rather than active planting can reduce costs by $77 \%$ (ref. ${ }^{73}$ ). Similarly, some lands may have limited value for human uses and thus lower opportunity $\operatorname{costs}^{74}$, although if these lands are highly degraded they may face higher implementation costs to enable ecosystem recovery. Finally, high material and labour costs associated with active restoration efforts can represent employment and economic opportunities.
From a feasibility perspective, restoration NCS may require shifting land use, which can face a host of cultural, social and economic barriers. For example, some higher-end estimates of mitigation potential from reforestation assume that pasture in historically forested areas can be returned to forest, due to improved efficiencies in livestock production or a shift towards plant-based diets $s^{8,30}$. Yet, alternative scenarios are possible where the future extent of the agricultural lands remains constant or increases ${ }^{75}$. Land use will also influence the likelihood of leakage, although restoring degraded lands could have lower leakage risks than lands with a high human land use value. Moreover, landscape-level planning that simultaneously balances multiple criteria, such as climate mitigation, cost and biodiversity conservation, can improve the overall outcomes compared with those of non-systematic planning ${ }^{76}$. For example, coordinated restoration across the Brazilian Atlantic Forest can increase biodiversity benefits by $257 \%$, double climate mitigation potential and reduce costs by $57 \%$ compared with those of uncoordinated action by individual land managers ${ }^{76}$.

In addition to cost and feasibility constraints, the time horizon for mitigation from restoration is generally longer than those for improved management or protection NCS. Although there are some examples of rapid removals, such as secondary tropical forests recovering in sites conducive to growth, carbon accumulation will take longer in slower-growing forest types or in places with degraded conditions ${ }^{46}$. Similarly, although restoration of inland wetlands can reduce $\mathrm{CO}_{2}$ emissions relative to those of disturbed sites, it can take decades or centuries to achieve a net cooling effect given the initial releases of methane after restoration ${ }^{77}$. Moreover, sequestration rates of restored wetlands seldom achieve the same level as those of similar natural wetlands ${ }^{78}$.

When done properly, restoration has the potential to offer high co-benefits, particularly in regions that have experienced severe loss and degradation of the native vegetation ${ }^{79}$. Restoring tree cover in urban landscapes can capture carbon ${ }^{6,7}$, improve air and water quality, and reduce urban heat effects ${ }^{80-82}$. Restoration of forest cover can also provide habitat for biodiversity, as well as an improved flow regulation of water ${ }^{83}$. Restoration of coastal wetlands can protect coastal communities from storm surge and erosion ${ }^{56}$. However, restoration NCS may not achieve the same level of co-benefits as those observed in protection NCS. Restoration often does not bring back the full function of undisturbed ecosystems ${ }^{79}$, and longer time horizons and spatial trade-offs can limit the co-benefits ${ }^{84}$.

\section{Applying the hierarchy in practice}

The NCS hierarchy is a general framework for considering how to prioritize NCS-not a pre-determined outcome of that prioritization. From a climate mitigation perspective, the generic NCS hierarchy is better suited to locations with high land-conversion pressures. For example, Borneo has high deforestation rates due to the expansion of industrial plantations and a need for regulatory and enforcement reforms ${ }^{85}$. Although improved forest management can alleviate some deforestation pressures ${ }^{86}$, insufficient protections put all forests-intact, managed and restored-at risk of conversion.

In other locations, it may be possible to deprioritize protection or improved management NCS. For example, in Gabon, deforestation pressures are low and the four criteria that inform location within the hierarchy point towards improved management NCS. Specifically, improved forest management has the largest mitigation potential ${ }^{87}$ and is immediately available via reduced-impact logging practices $^{88}$, which are low cost and deliver many co-benefits ${ }^{17}$.

There are also some countries in which restoration opportunities are much larger than either protection or improved management opportunities $^{53}$. For example, restoring forest cover in Ethiopia could provide up to $22.0 \mathrm{MtCO}_{2} \mathrm{yr}^{-1}$ in 2030, compared with $8.4 \mathrm{MtCO}_{2} \mathrm{yr}^{-1}$ for avoided deforestation and $7.5 \mathrm{MtCO}_{2} \mathrm{yr}^{-1}$ for improved forest management at $\leq \mathrm{US} \$ 100 \mathrm{tCO}_{2} \mathrm{e}^{-1}$ (ref. ${ }^{89}$ ). Further, 
at US $\$ 20 \mathrm{tCO}_{2} \mathrm{e}^{-1}$, reforestation in Ethiopia offers 25\% more mitigation potential than avoided deforestation ${ }^{54}$.

Beyond climate mitigation, we also acknowledge that context can result in a prioritization scheme that differs from the NCS hierarchy. For example, it can take years for communities to build up the infrastructure and social capital needed to restore forests at scale ${ }^{90}$. Given the historical momentum, it may make sense to continue to focus on restoration in such a location, while also considering opportunities to protect ecosystems or improve the management of working lands. Ultimately, the ability to act sooner rather than later by adopting the most feasible actions is critical, as the window to constrain warming below catastrophic levels is narrowing ${ }^{33}$. Land-based mitigation actions will be most effective if undertaken in the next decade ${ }^{8}$.

Finally, the NCS hierarchy is intended to guide a decision-making process that flows from protection to improved management to restoration, but also considers whether and how to use all three categories. The best approach is probably to advance a portfolio of $\mathrm{NCS}^{91}$. Although we partition protection, improved management and restoration, a mix of NCS may be required at the project and landscape levels to achieve mitigation goals. For example, where forests are cleared primarily for agricultural land or wood fuel, avoiding forest conversion typically requires improved management of degraded agricultural lands or restoration of tree cover to meet the needs of local communities ${ }^{10}$. There is no universal panacea to climate change, so a balanced approach across NCS may best optimize carbon and non-carbon benefits, as well as local needs. Further, NCS with a longer time horizon (such as reforestation) must be started now to reap the benefits in a timely manner ${ }^{33}$. Coupling more immediate NCS with those that have a longer time horizon, but higher mitigation potential, may lead to the best long-term outcomes.

Priorities within the NCS hierarchy also probably differ between public and private sector actors. For example, restoration actions, such as tree planting, are a common way to improve corporate image $^{92,93}$ and some corporate actors view restoration NCS as an underdeveloped sector of the carbon market that needs investment now to tap its future potential (for example, ref. ${ }^{94}$ ). Private sector actors may also prefer improved management NCS because they may be subject to fewer social and cultural constraints, such as changes in land use, and involve non-carbon financial returns over time (for example, ref. ${ }^{95}$ ). However, public actors may be best positioned for protection NCS, given that these often require policy mechanisms capable of addressing landscape-scale issues linked to leakage and social-institutional or policy-regulatory feasibility constraints ${ }^{96}$. However, a coordinated effort across all actors will lead to better outcomes. The Science-Based Targets Initiative has methods for corporates to develop $1.5-^{\circ} \mathrm{C}$-relevant mitigation targets that align with global commitments, and will issue specific guidance in 2022 for the agriculture and forestry sectors to address supply-chain emissions from land use.

Finally, carbon credit certifications may also prioritize actions differently than the NCS hierarchy. Additionality is essential. To reduce net emissions and reach neutrality by 2050 , the global community must take steps beyond business as usual. However, the additionality criterion risks creating perverse incentives, and may, for example, lead to a preference for restoration over protection NCS if 'doing' restoration is perceived as more additional than 'stopping' conversion or disturbance. Similarly, the additionality criterion may lead to a preference for labour- or resource-intensive restoration if, for example, tree planting is viewed as more additional than natural forest regrowth. Finally, actors in degraded or at-risk systems have the opportunity to demonstrate how additional action would restore and protect natural lands ${ }^{49}$. In contrast, Indigenous or traditional rural communities may be excluded from incentive mechanisms, such as carbon offsets, if their successful and long-standing traditions of protection and land management are not considered additional to the status quo. The solution is to continue to develop accounting and verification methodologies that minimize these perverse incentives, such as those that better-quantify stable carbon stocks in the climate ledger ${ }^{49}$.

\section{Comparison of biodiversity and NCS hierarchies}

The original biodiversity hierarchy highlighted several key challenges beyond additionality. These included selecting an appropriate biodiversity metric, demonstrating equivalency between biodiversity losses and gains, and identifying the appropriate multiplication factor for biodiversity gains required by offset projects ${ }^{14}$. These challenges are reduced for the NCS hierarchy, in which $\mathrm{CO}_{2} \mathrm{e}$ serves as a more universal currency to measure climate impacts within the NCS hierarchy. However, we note emerging research that flags the weaker climate mitigation effect of carbon removals compared with that of avoided emissions when removals are deployed at large scales ${ }^{64}$. Moreover, other factors beyond $\mathrm{CO}_{2} \mathrm{e}$, such as biodiversity and other co-benefits, can and do influence decisions about the merits of different NCS projects.

The biodiversity hierarchy also includes a final 'offset' step in which the remaining negative impacts on biodiversity are supposedly countered by conservation efforts elsewhere ${ }^{14,97}$. We do not include an 'offset' stage within the NCS hierarchy. The NCS hierarchy can be used to prioritize action within a geography or company's supply chain, as well as to prioritize climate offsets elsewhere to compensate for unavoidable emissions. Thus, including an offset step within the NCS hierarchy itself leads to circularity. However, we flag that GHG offsets should (1) only be used after an entity has implemented all the possible emission reductions from their footprint, (2) ensure that environmental issues are not exported from one community or sector to another, (3) equitably and fairly benefit local communities, and (4) be planned with the NCS hierarchy in $\operatorname{mind}^{3}$.

\section{Conclusion}

Preventing catastrophic climate warming will require radical transformation across all sectors-energy, industry, transportation and land ${ }^{1}$. NCS do not replace or delay the deep decarbonization needed to achieve the 2015 Paris Agreement goal to keep global warming well below $2{ }^{\circ} \mathrm{C}$ (ref. ${ }^{98}$ ). However, they do represent a promising set of options to constrain the climate crisis and also help to conserve biodiversity. Although there are many reasons why individual decision-makers may choose to adopt different prioritization schemes, considering the NCS hierarchy will help these land-based options reach their highest potential.

\section{Data availability}

Data underlying Fig. 2 and Supplementary Figs. 2 and 3 are available as Supplementary Data.

Received: 31 March 2021; Accepted: 27 September 2021; Published online: 18 November 2021

\section{References}

1. IPCC Special Report on Global Warming of $1.5^{\circ} \mathrm{C}$ (eds Masson-Delmotte, V. et al.) (WMO, 2018).

2. Anderson, C. M. et al. Natural climate solutions are not enough. Science 363, 933-934 (2019).

3. Carton, W., Lund, J. F. \& Dooley, K. Undoing equivalence: rethinking carbon accounting for just carbon removal. Front. Clim. 3, 30 (2021).

4. Seddon, N. et al. Getting the message right on nature-based solutions to climate change. Glob. Change Biol. 27, 1518-1546 (2021).

5. Griscom, B. W. et al. We need both natural and energy solutions to stabilize our climate. Glob. Change Biol. 25, 1889-1890 (2019).

6. Fargione, J. et al. Natural climate solutions for the United States. Sci. Adv. 4, eaat1869 (2018).

7. Drever, C. R. et al. Natural climate solutions for Canada. Sci. Adv. 7, eabd6034 (2021). 
8. Griscom, B. W. et al. Natural climate solutions. Proc. Natl Acad. Sci. USA 114, 11645-11650 (2017).

9. Fuss, S. et al. Negative emissions-Part 2: costs, potentials and side effects. Environ. Res. Lett. 13, 63002 (2018).

10. Gregorio, N. et al. in Enhancing Food Security Through Forest Landscape Restoration: Lessons from Burkina Faso, Brazil, Guatemala, Viet Nam, Ghana, Ethiopia and Philippines (eds Kumar, C. et al.) 174-217 (IUCN, 2015).

11. Meyer, J. M. Gifford Pinchot, John Muir, and the boundaries of politics in American thought. Polity 30, 267-284 (1997).

12. Standard on Biodiversity Offsets (BBOP, 2012)

13. Performance Standard 6: Biodiversity Conservation and Sustainable Management of Natural Resources (IFC, 2012).

14. Arlidge, W. N. S. et al. A global mitigation hierarchy for nature conservation. Bioscience 68, 336-347 (2018).

15. Science-Based Targets for Nature: Initial Guidance for Business (Science Based Targets Network, 2020)

16. Seddon, N. et al. Understanding the value and limits of nature-based solutions to climate change and other global challenges. Phil. Trans. R. Soc. B 375, 20190120 (2020).

17. Ellis, P. W. et al. Reduced-impact logging for climate change mitigation (RIL-C) can halve selective logging emissions from tropical forests. Ecol. Manag. 438, 255-266 (2019).

18. Martin, D. M. Ecological restoration should be redefined for the twenty-first century. Restor. Ecol. 25, 668-673 (2017).

19. Veldman, J. W. et al. Where tree planting and forest expansion are bad for biodiversity and ecosystem services. Bioscience 65, 1011-1018 (2015).

20. Supporting Canadians and Fighting COVID-19 (Department of Finance Canada, 2020).

21. Roe, S. et al. Contribution of the land sector to a $1.5^{\circ} \mathrm{C}$ world. Nat. Clim. Change 9, 817-828 (2019).

22. Seddon, N. et al. Nature-Based Solutions in Nationally Determined Contributions: Synthesis and Recommendations for Enhancing Climate Ambition and Action by 2020 (IUCN, 2019).

23. Carbon Removal Corporate Action Tracker (Institute for Carbon Removal Law and Policy, accessed 6 July 2021); https://research.american.edu/ carbonremoval/2020/05/07/carbon-removal-corporate-action-tracker/

24. Pendrill, F. et al. Agricultural and forestry trade drives large share of tropical deforestation emissions. Glob. Environ. Change 56, 1-10 (2019).

25. Goal 1 Assessment: Striving to End Natural Forest Loss (NYDF Progress Assessment Secretariat, 2020)

26. Smith, B. One year later: The path to carbon negative-a progress report on our climate 'moonshot'. Microsoft Blog (28 January 2021); https://blogs. microsoft.com/blog/2021/01/28/

one-year-later-the-path-to-carbon-negative-a-progress-report-on-our-climatemoonshot/

27. Ward, C. et al. Smallholder perceptions of land restoration activities: rewetting tropical peatland oil palm areas in Sumatra. Indonesia. Reg. Environ. Change 21, 1 (2020).

28. Jacobson, M. \& Ham, C. The (un)broken promise of agroforestry: a case study of improved fallows in Zambia. Environ. Dev. Sustain. 22, 8247-8260 (2020).

29. West, T. A. P., Börner, J., Sills, E. O. \& Kontoleon, A. Overstated carbon emission reductions from voluntary REDD+ projects in the Brazilian Amazon. Proc. Natl Acad. Sci USA 117, 24188-24194 (2020).

30. Cook-Patton, S. C. et al. Lower cost and more feasible options to restore forest cover in the contiguous United States for climate mitigation. One Earth 3, 739-752 (2020)

31. Petersen, S. O., Højberg, O., Poulsen, M., Schwab, C. \& Eriksen, J. Methanogenic community changes, and emissions of methane and other gases, during storage of acidified and untreated pig slurry. J. Appl. Microbiol. 117, 160-172 (2014)

32. Günther, A. et al. Prompt rewetting of drained peatlands reduces climate warming despite methane emissions. Nat. Commun. 11, 1644 (2020).

33. Qin, Z. et al. Delayed impact of natural climate solutions. Glob. Change Biol. 27, 215-217 (2021)

34. Anderegg, W. R. L. et al. Climate-driven risks to the climate mitigation potential of forests. Science 368, eaaz7005 (2020).

35. Pagiola, S., Honey-Rosés, J. \& Freire-González, J. Assessing the permanence of land-use change induced by payments for environmental services: evidence from Nicaragua. Trop. Conserv. Sci. https://doi.org/10.1177/1940082920922676 (2020).

36. Tseng, T.-W. J. et al. Influence of land tenure interventions on human well-being and environmental outcomes. Nat. Sustain. 4, 242-251 (2021).

37. Smith, P. et al. Impacts of land-based greenhouse gas removal options on ecosystem services and the United Nations Sustainable Development Goals. Annu. Rev. Environ. Resour. 44, 255-286 (2019).

38. Nunez, S., Verboom, J. \& Alkemade, R. Assessing land-based mitigation implications for biodiversity. Environ. Sci. Policy 106, 68-76 (2020).

39. Chausson, A. et al. Mapping the effectiveness of nature-based solutions for climate change adaptation. Glob. Change Biol. 26, 6134-6155 (2020)
40. Infield, M., Entwistle, A., Anthem, H., Mugisha, A. \& Phillips, K. Reflections on cultural values approaches to conservation: lessons from 20 years of implementation. Oryx 52, 220-230 (2018).

41. Rosenstock, T. S. et al. A planetary health perspective on agroforestry in sub-Saharan Africa. One Earth 1, 330-344 (2019).

42. Garrett, H. E. et al. Hardwood silvopasture management in North America. Agrofor. Syst. 61, 21-33 (2004).

43. Kroeger, T. et al. Returns on investment in watershed conservation: application of a best practices analytical framework to the Rio Camboriú Water Producer program, Santa Catarina, Brazil. Sci. Total Environ. 657, 1368-1381 (2019)

44. Lamb, D., Erskine, P. D. \& Parrotta, J. A. Restoration of degraded tropical forest landscapes. Science 310, 1628-1632 (2005).

45. Ferreira, J. et al. Carbon-focused conservation may fail to protect the most biodiverse tropical forests. Nat. Clim. Change 8, 744-749 (2018).

46. Cook-Patton, S. C. et al. Mapping carbon accumulation potential from global natural forest regrowth. Nature 585, 545-550 (2020).

47. Wilson, S. J., Schelhas, J., Grau, R., Nanni, A. S. \& Sloan, S. Forest ecosystem-service transitions: the ecological dimensions of the forest transition. Ecol. Soc. 22, 38 (2017).

48. Funk, J. M. et al. Securing the climate benefits of stable forests. Clim. Policy 19, 845-860 (2019).

49. Keith, H. et al. Evaluating nature-based solutions for climate mitigation and conservation requires comprehensive carbon accounting. Sci. Total Environ. 769, 144341 (2021).

50. Moomaw, W. R., Masino, S. A. \& Faison, E. K. Intact forests in the United States: proforestation mitigates climate change and serves the greatest good. Front. For. Glob. Change 2, 27 (2019).

51. Hiraishi, T. et al. 2013 Supplement to the 2006 IPCC Guidelines for National Greenhouse Gas Inventories: Wetlands (WMO, 2013).

52. Goldstein, A. et al. Protecting irrecoverable carbon in Earth's ecosystems. Nat. Clim. Change 10, 287-295 (2020).

53. Griscom, B. W. et al. National mitigation potential from natural climate solutions in the tropics. Phil. Trans. R. Soc. B 375, 20190126 (2020).

54. Busch, J. et al. Potential for low-cost carbon dioxide removal through tropical reforestation. Nat. Clim. Change 9, 463-466 (2019).

55. Vargas Zeppetello, L. R. et al. Large scale tropical deforestation drives extreme warming. Environ. Res. Lett. 15, 84012 (2020).

56. Spalding, M. D. et al. The role of ecosystems in coastal protection: adapting to climate change and coastal hazards. Ocean Coast. Manag. 90, 50-57 (2014)

57. Watson, J. E. M. et al. The exceptional value of intact forest ecosystems. Nat. Ecol. Evol. 2, 599-610 (2018).

58. Global Assessment Report on Biodiversity and Ecosystem Services (IPBES, 2019).

59. Dobson, A. P. et al. Ecology and economics for pandemic prevention. Science 369, 379-381 (2020).

60. Streck, C. REDD+ and leakage: debunking myths and promoting integrated solutions. Clim. Policy 21, 843-852 (2021).

61. Brancalion, P. H. S. et al. The cost of restoring carbon stocks in Brazil's Atlantic Forest. Land Degrad. Dev. 32, 830-841 (2021)

62. Bustamante-Sánchez, M. A. \& Armesto, J. J. Seed limitation during early forest succession in a rural landscape on Chiloé Island, Chile: implications for temperate forest restoration. J. Appl. Ecol. 49, 1103-1112 (2012).

63. Koch, A., Brierley, C. \& Lewis, S. L. Effects of Earth system feedbacks on the potential mitigation of large-scale tropical forest restoration. Biogeosciences 18, 2627-2647 (2021)

64. Zickfeld, K., Azevedo, D., Mathesius, S. \& Matthews, H. D. Asymmetry in the climate-carbon cycle response to positive and negative $\mathrm{CO}_{2}$ emissions. Nat. Clim. Change 11, 613-617 (2021).

65. Johnson, K. A. et al. A benefit-cost analysis of floodplain land acquisition for US flood damage reduction. Nat. Sustain. 3, 56-62 (2020).

66. Nolte, C. High-resolution land value maps reveal underestimation of conservation costs in the United States. Proc. Natl Acad. Sci. USA 117, 29577-29583 (2020)

67. Reetz, H., Heffer, P. \& Bruulsema, T. in Managing Water and Fertilizer for Sustainable Agricultural Intensification (eds Drechsel, P. et al.) 65-86 (IFA IWMI, IPNI and IPI, 2015).

68. Sharma, P. et al. The role of cover crops towards sustainable soil health and agriculture-a review paper. Am. J. Plant Sci. 09, 1935-1951 (2018).

69. Bergeron, M. et al. Reduced soil nutrient leaching following the establishment of tree-based intercropping systems in eastern Canada. Agrofor. Syst. 83, 321-330 (2011)

70. Moore, A. A. \& Palmer, M. A. Invertebrate biodiveristy in agricultural and urban headwater streams: implications for conservation and management. Ecol. Appl. 15, 1169-1177 (2005).

71. Martin, M. P. et al. People plant trees for utility more often than for biodiversity or carbon. Biol. Conserv. 261, 109224 (2021).

72. Mendes, T. P., de Assis Montag, L. F., Alvarado, S. T. \& Juen, L. Assessing habitat quality on alpha and beta diversity of Odonata larvae (Insect) in logging areas in Amazon forest. Hydrobiologia 848, 1147-1161 (2021). 
73. Crouzeilles, R. et al. Achieving cost-effective landscape-scale forest restoration through targeted natural regeneration. Conserv. Lett. 13, e12709 (2020).

74. Gilroy, J. J. et al. Cheap carbon and biodiversity co-benefits from forest regeneration in a hotspot of endemism. Nat. Clim. Change 4, 503-507 (2014)

75. Riahi, K. et al. The Shared Socioeconomic Pathways and their energy, land use, and greenhouse gas emissions implications: an overview. Glob. Environ. Change 42, 153-168 (2017).

76. Strassburg, B. B. N. et al. Strategic approaches to restoring ecosystems can triple conservation gains and halve costs. Nat. Ecol. Evol. 3, 62-70 (2019).

77. Taillardat, P., Thompson, B. S., Garneau, M., Trottier, K. \& Friess, D. A. Climate change mitigation potential of wetlands and the cost-effectiveness of their restoration. Interface Focus 10, 20190129 (2020).

78. Xu, S., Liu, X., Li, X. \& Tian, C. Soil organic carbon changes following wetland restoration: a global meta-analysis. Geoderma 353, 89-96 (2019).

79. Holl, K. D. \& Brancalion, P. H. S. Tree planting is not a simple solution. Science 368, 580-581 (2020)

80. Kroeger, T., McDonald, R. I., Boucher, T., Zhang, P. \& Wang, L. Where the people are: current trends and future potential targeted investments in urban trees for $\mathrm{PM}_{10}$ and temperature mitigation in 27 U.S. cities. Landsc. Urban Plan. 177, 277-240 (2018).

81. McDonald, R. I., Kroeger, T., Zhang, P. \& Hamel, P. The value of US urban tree cover for reducing heat-related health impacts and electricity consumption. Ecosystems 23, 137-150 (2020).

82. Heris, M. et al. Piloting urban ecosystem accounting for the United States. Ecosyst. Serv. 48, 101226 (2021).

83. Ellison, D. et al. Trees, forests and water: cool insights for a hot world. Glob. Environ. Change 43, 51-61 (2017).

84. Li, R. et al. Time and space catch up with restoration programs that ignore ecosystem service trade-offs. Sci. Adv. 7, eabf8650 (2021).

85. Gaveau, D. L. A. et al. Rise and fall of forest loss and industrial plantations in Borneo (2000-2017). Conserv. Lett. 12, e12622 (2019).

86. Griscom, B. W., Goodman, R. C., Burivalova, Z. \& Putz, F. E. Carbon and biodiversity impacts of intensive versus extensive tropical forestry. Conserv. Lett. 11, e12362 (2018).

87. Gabon's Proposed National RED+ Forest Reference Level (Gabonese Republic, 2021).

88. Umunay, P., Gregoire, T., Gopalakrishna, T., Ellis, P. \& Putz, F. Selective logging emissions and potential emission reductions from reduced-impact logging in the Congo Basin. Ecol. Manag. 437, 360-371 (2019).

89. Natural Climate Solutions World Atlas (Nature4Climate, accessed 9 December 2020); https://nature4climate.org/n4c-mapper/

90. Dave, R. et al. Second Bonn Challenge Progress Report: Application of the Barometer in 2018 (IUCN, 2019); https://doi.org/10.2305/IUCN.CH.2019.06.en

91. Kremen, C. \& Merenlender, A. M. Landscapes that work for biodiversity and people. Science 362, eaau6020 (2018).
92. Seymour, F. Seeing the forests as well as the (trillion) trees in corporate climate strategies. One Earth 2, 390-393 (2020).

93. Kronenberg, J. \& Mieszkowicz, J. Planting trees for publicity-how much are they worth? Sustainability 3, 1022-1034 (2011).

94. Microsoft Carbon Removal: Lessons from an Early Corporate Purchase (Microsoft, 2021)

95. Toor, I. A., Smith, E. G., Whalen, J. K. \& Naseem, A. Tree-based intercropping in southern Ontario, Canada. Can. J. Agric. Econ. 60, 141-154 (2012).

96. Watson, J. E. M., Dudley, N., Segan, D. B. \& Hockings, M. The performance and potential of protected areas. Nature 515, 67-73 (2014).

97. zu Ermgassen, S. O. S. E. et al. The ecological outcomes of biodiversity offsets under "no net loss" policies: a global review. Conserv. Lett. 12, e12664 (2019).

98. Adoption of the Paris Agreement FCCC/CP/2015/L.9/Rev.1 (UNFCCC, 2015).

\section{Acknowledgements}

This paper was developed with funding from the Government of Norway, although it does not necessarily reflect their views or opinions. Funding from the International Paper and the Bezos Earth Fund also supported this work. We thank R. Ellis for helping to develop the idea and J. Howard, F. Putz, W. Turner, M. C. Weikel and A. Wu for their critical reviews.

\section{Author contributions}

P.W.E. proposed the initial idea. S.C.C.-P. further developed the idea and wrote the manuscript. T.K. conducted the economic analyses. S.Y. created Fig. 2 and all the Supplementary figures. All the co-authors contributed ideas and revised the manuscript.

\section{Competing interests}

The authors declare no competing interests.

\section{Additional information}

Supplementary information The online version contains supplementary material available at https://doi.org/10.1038/s41558-021-01198-0.

Correspondence should be addressed to Susan C. Cook-Patton.

Peer review information Nature Climate Change thanks Sarah Wilson, Pedro Brancalion and Alison Smith for their contribution to the peer review of this work.

Reprints and permissions information is available at www.nature.com/reprints.

Publisher's note Springer Nature remains neutral with regard to jurisdictional claims in published maps and institutional affiliations.

(C) Springer Nature Limited 2021 